\title{
Saúde mental e espiritualidade/religiosidade: a visão de psicólogos
}

\author{
Márcia Regina de Oliveira \\ José Roque Junges \\ Universidade do Vale do Rio dos Sinos
}

\begin{abstract}
Resumo
A espiritualidade está sendo sempre mais pesquisada em sua relação com a saúde mental. O objetivo da pesquisa é descrever como os psicólogos percebem em suas práticas a relação entre espiritualidade/ religiosidade e a saúde mental. Trata-se de um estudo exploratório com abordagem qualitativa. A amostra foi composta por 2 grupos de profissionais graduados em Psicologia. Um grupo foi formado por 5 psicólogos do Centro de Atenção Psicossocial de São Leopoldo, o outro por 5 psicólogos de clínicas particulares, selecionados segundo o método da "bola de neve", pelo qual o primeiro é escolhido por conveniência, este indica outro e assim por diante. Os dados foram coletados através de entrevista semiestruturada e interpretados segundo a análise de conteúdo, identificando três categorias temáticas: 1) Saúde mental como equilíbrio e sentido da vida; 2) Espiritualidade/Religiosidade como experiência; 3) Clínica como autoconhecimento e como autonomia.
\end{abstract}

Palavras-chave: psicologia; espiritualidade; saúde mental; clínica; psicopatologia.

\begin{abstract}
Mental health and spirituality/religiosity: psychologists' understandings. Spirituality has been more and more researched in its relations with mental health. The objective of the research is to describe how the psychologists realize in their practices the relationship between religiosity/spirituality and mental health. It is an exploratory study with qualitative approach. The sample has been composed by two groups of professionals of psychology. One group has been formed by all the 5 psychologist of the Public Mental Health Service of São Leopoldo and the other by 5 psychologists of private clinics, selected by the method named "snow ball" by which the first is chosen by convenience and this one indicate the second and so on. The dates have been collected by semi-structured interview and interpreted according the content analysis, identifying three subject matter categories: 1) Mental health as equilibrium and sense of life; 2) Spirituality/ religiosity as experience; 3) Clinic as becoming aware of the self and autonomy.
\end{abstract}

Keywords: psychology; spirituality; mental health; clinic; psychopathology.

\section{Introdução}

O contexto sociocultural da pós-modernidade coloca o ser humano diante de uma crise de identidade. Apesar do alto grau de independência e domínio, possibilitado pela ciência e a técnica, os indivíduos vivem numa situação de desamparo e ansiedade existencial (Giddens 2002). Como reação a essa sensação de desamparo, constata-se o surgimento de uma forte tendência de busca de valores sobrenaturais do mundo da religiosidade, fenômeno denominado por Berger (1997) um rumor de anjos. Essa tendência leva a um crescente interesse acadêmico por pesquisar esse fenômeno devido a suas implicações para o bem estar e a qualidade de vida das pessoas. Essa relação entre saúde e religiosidade/espiritualidade torna-se um campo de estudo promissor, ao mesmo tempo controverso e desafiador (MoreiraAlmeida, 2007).

Nos últimos tempos, a psicologia tem se voltado ao estudo da espiritualidade/religiosidade e sua relação com a saúde mental, o bem estar psicológico e a integração bio-psicosocio-espiritual do ser humano. Segundo Lancetti e Amarante (2006), pode-se identificar a saúde mental como uma "mente saudável”. Esta mente saudável seria o movimento contínuo do sujeito em busca de um bem estar, de modos de vida que o sustentem diante das adversidades do cotidiano e que o ajudem num processo de mudança e produção da subjetividade e não como mera ausência de doenças. Essa visão está próxima da noção de "qualidade de vida", seguindo a perspectiva de Minayo, Hartz e Buss (2000) e abrindo, assim, espaço para se pensar também o papel da espiritualidade na saúde mental. Em 1988, a Organização Mundial de Saúde (OMS), incluiu a dimensão espiritual no conceito multidimensional de saúde, remetendo a questões como significado e sentido da vida, e não se limitando a qualquer tipo específico de crença ou prática religiosa. Para ela, a espiritualidade é o conjunto de todas as emoções e convicções 
de natureza não material, com a suposição de que há mais no viver do que pode ser percebido ou plenamente compreendido (Volcan, Sousa, Mari, \& Lessa, 2003).

Para entender bem o termo espiritualidade, é necessário distingui-lo de religião. O conceito de religião refere-se ao aspecto institucional e doutrinário de determinada forma de vivência religiosa. Define-se por determinadas crenças e ritos referidos ao transcendente e entendidos como meios que oferecem salvação. (Boff, 2006; Libanio, 2002).

No início do século XX, Otto (1915/1985) inaugurou um novo modo de estudar o fenômeno religioso, continuado depois por Eliade (1992). Eles se apartaram das análises tradicionais que enfatizavam a comparação entre as diferentes religiões para apontar as diferenças. Esse novo enfoque punha o acento na experiência religiosa que teria elementos semelhantes em todas as religiões.

Todas as religiões têm como base a experiência com uma realidade misteriosa e fascinante que se apodera do ser humano, manifestando a presença de algo transcendente que é sentido no cotidiano da existência humana e com grande capacidade de transformar a vida. A espiritualidade refere-se a essa experiência de contato com algo que transcende as realidades normais da vida. Significa experimentar uma força interior que supera as próprias capacidades (Boff, 2006).

A espiritualidade manifesta-se como religiosa, quando essa transcendência repercute de tal forma na transformação da vida da pessoa que o experimentado não se explica apenas por forças contidas na interioridade da pessoa, mas é sentido como a presença de um absoluto, identificado como Deus. Essa forma de espiritualidade foi também chamada de mística (Vasconcelos, 2006).

Portanto, a espiritualidade e a religiosidade caracterizamse pela dimensão essencialmente experiencial, enquanto que a religião está calcada no aspecto institucional e doutrinário. $\mathrm{O}$ presente artigo estará focado na espiritualidade/religiosidade em sua relação com a saúde mental e não no fenômeno da religião.

A influência da religiosidade sobre a saúde mental é um fenômeno resultante de vários fatores como: estilo de vida, suporte social, um sistema de crenças, práticas religiosas, formas de expressar estresse, direção e orientação espiritual (MoreiraAlmeida, Lotufo Neto, \& Koenig, 2006). Stroppa e MoreiraAlmeida (2008) demonstram que muitos estudos apontam, em seus resultados, que maiores níveis de envolvimento religioso estão associados positivamente a indicadores de bem-estar psicológico, como satisfação com a vida, afeto positivo e moral elevado, felicidade, melhor saúde física e mental.

Dalgalarrondo (2007) afirma que a presença do elemento religioso no modo de construir, enfrentar e vivenciar o sofrimento mental foi observado por muitos pesquisadores. Esse é o caso tanto de estudos com contornos mais qualitativos e etnográficos, como com os mais bem quantitativos e epidemiológicos. Isso também é constatável tanto para os transtornos mentais mais leves, como ansiedade e depressão, como para os quadros graves, como nas psicoses.

Lukoff (2003) mostra que muitas pesquisas revelam boas correlações entre saúde e espiritualidade. Portanto, existe a necessidade de incluir a espiritualidade como um recurso de saúde e a inclusão desta temática já na formação acadêmica, provocando reflexão e questionamento sobre a dimensão espiritual do ser humano.

Panzini e Bandeira (2005) dizem que vários estudos de saúde pública demonstram que pessoas que apresentam envolvimento religioso têm menor probabilidade de apresentar comportamentos de risco, como violência, delinquência e crime, o uso e abuso de substâncias que criam dependência como álcool e droga. Além disso, a grande maioria dos usuários de serviços de saúde, avaliados em 350 estudos científicos, quer ser perguntada sobre sua espiritualidade e/ou suas crenças religiosas no contexto do cuidado à saúde (Connelly \& Light, 2003).

O objetivo do artigo é apresentar como psicólogos percebem em suas práticas a relação entre saúde mental e espiritualidade/ religiosidade. Na pesquisa, partiu-se da hipótese de uma possível diferença entre a percepção dos psicólogos do CAPS e das clínicas privadas, sobre a relação entre a saúde mental e a espiritualidade/religiosidade, por isso, foram entrevistados profissionais destes dois setores para a coleta de dados.

\section{Metodologia}

A pesquisa é um estudo exploratório comparativo com abordagem qualitativa. O universo empírico foi composto por dois grupos de profissionais graduados em Psicologia. O $1^{\underline{o}}$ grupo formado por cinco psicólogos contratados pela Prefeitura Municipal de São Leopoldo (RS) com mais tempo de atuação no Centro de Atenção Psicossocial (CAPS) Capilé, que atende portadores de sofrimento psíquico grave que estejam em crise, a partir dos 16 anos. O $2^{\underline{0}}$ grupo, composto por cinco psicólogos que atuam exclusivamente em clínicas particulares. Esses últimos participantes foram selecionados segundo o método da "bola de neve", pelo qual o primeiro é escolhido por conveniência e este indica outro, que por sua vez indica outro, e assim por diante até alcançar cinco profissionais.

Os dados foram coletados através de entrevista semiestruturada, seguindo um roteiro com as seguintes questões: Conceito de espiritualidade/religiosidade; Relação entre espiritualidade/religiosidade e saúde mental; Espiritualidade/ religiosidade na prática clínica do psicólogo; Espiritualidade/ religiosidade no processo terapêutico do usuário; Espiritualidade/ religiosidade na atividade do psicólogo.

As entrevistas foram gravadas e depois transcritas. As falas transcritas foram codificadas em categorias para responder aos objetivos específicos do estudo e interpretadas segundo a análise de conteúdo (Minayo, 2000).

O projeto foi aprovado pelo Comitê de Ética em pesquisa da Unisinos com a resolução CEP 09/065. Para salvaguardar a confidencialidade, a identidade dos entrevistados será preservada, usando nomes fictícios.

\section{Resultados}

No estudo, a religião aparece interligada com o tema, contudo, é importante salientar que a pesquisa não teve como foco a religião, mas a espiritualidade/religiosidade em sua relação com a saúde mental. 
Embora a pesquisa tenha partido da hipótese de que haveria diferença quanto à concepção de espiritualidade/religiosidade entre os psicólogos dos CAPS e das clínicas particulares, os resultados não evidenciaram essa hipótese, como aparecerá na citação das falas dos dois grupos.

A partir da análise de conteúdo das entrevistas, foram identificadas três categorias: 1) Saúde mental como equilíbrio e sentido da vida; 2) Espiritualidade/Religiosidade como experiência; 3) Clínica como autoconhecimento e como autonomia.

\section{Saúde mental como equilibrio e sentido da vida}

De acordo com todos os entrevistados, saúde mental é o equilíbrio entre todas as dimensões da vida e a capacidade de se abrir às mudanças e às novas experiências que a vida proporciona. Foi salientado por alguns entrevistados que a espiritualidade/religiosidade exerce uma função fundamental para a harmonia e o equilíbrio entre as dimensões do ser humano. Ricardo expressou:

Acredito que a saúde mental é um estágio em que o sujeito se encontra em equilíbrio, dentro de todos esses fatores que a gente falou, fator comportamental, fator cognitivo, fator afetivo, fator familiar, fator biológico, espiritual também. (...) A espiritualidade está a favor da mudança e promove mudança.

A busca pelo sentido da vida foi relatada em todas as entrevistas, em algumas de forma direta e em outras através de reflexões, apontando para a espiritualidade como aquela que auxilia no processo de busca de sentido e saúde mental. Fernando disse: "A questão de achar um sentido para a vida passa muito pela questão da espiritualidade".

Ficou bastante expressivo no relato dos entrevistados que a busca por um sentido de viver está relacionada à experiência do vazio existencial e da posição de desamparo do sujeito, bem como a busca por respostas às questões existenciais do ser humano. Fernando falou: "Dar alguma explicação para algumas questões que afinal a gente não consegue entender bem: De onde eu venho? Porque estou aqui? Qual a razão da minha existência?". A queda das instituições, entre elas as religiões, que antes davam conta de responder aos anseios do ser humano e hoje não exercem mais esse papel, foi apontada por grande parte dos participantes, como um fator importante que contribui para o sentimento de vazio e desamparo do sujeito, motivando para essa busca de espiritualidade e sentido do viver. Vera disse:

$\mathrm{O}$ vazio de que eu falei vem com a queda das instituições que organizavam a sociedade, a partir disso nada está garantido. (...) Justamente o ser humano se depara com o seu desamparo que é constituinte. Aí eu acho que a religiosidade/espiritualidade vem como uma tentativa de responder a esse desamparo.

No que se refere à saúde mental e sua relação com a espiritualidade/religiosidade, foi evidenciado que a experiência do sujeito e a forma como ele a sente e a interpreta é de suma importância para manter ou desenvolver comportamentos saudáveis ou desordenados, tanto no que se refere à espiritualidade/religiosidade como em outras dimensões da vida: "Vai depender da importância que a pessoa vai dar para estas questões" (Denise). Conforme os entrevistados, a inter-relação provoca o sujeito a um constante movimento de busca, encontro e sentido: "Tudo vai depender sempre de cada situação, de cada pessoa e da relação que faz com essa instituição ou com alguma coisa pra buscar sua espiritualidade" (Fernando).

\section{Espiritualidade/religiosidade como experiência}

Todos os entrevistados partiram da definição de que todo o ser humano possui uma dimensão espiritual. Para Vera: "É algo intrínseco às relações humanas". A espiritualidade/ religiosidade foi definida como uma energia vital, uma força relacionada com a forma como o sujeito acredita na vida e com a capacidade de direcionar essa força ao seu favor: "quando eu aposto que a vida tem força" (Irene). A palavra "experiência", para definir espiritualidade, esteve presente em todos os relatos, sendo entendida como encontro e sentimento de ligação com todas as coisas: "Relação com o mundo" (Adriana). Também foi lembrado que a espiritualidade é um fator de proteção que coopera para a mudança de vida e para a reabilitação: "É uma proteção" (Ricardo).

O conceito de imanência foi relacionado com a espiritualidade, englobando a ideia de Deus, não como algo que vem depois ou que está além, mas algo imanente. Adriana afirmou: "Deus está em todo o lugar porque ele faz parte dessa vida". Nesse sentido Deus é apresentado como sendo a própria natureza, as forças que operam no mundo: "Essas múltiplas forças que nos atravessam o tempo inteiro, que nos constituem" (Adriana). A espiritualidade se concretizaria no encontro com essas forças: "Essa relação com o mundo, com a vida" (Adriana). Ainda como definição de Deus surgiu que: "Deus é mistério" (Fernando).

Em síntese, a religiosidade, para a maioria dos entrevistados, seria a expressão da própria espiritualidade, enquanto que a religião foi definida pelo grupo entrevistado como um conjunto de dogmas e normas organizacionais: "Uma determinada religião, instituição religiosa, no sentido de terem uma sede, mas também de saberem uma doutrina toda que a envolve" (Salete).

Em todos os relatos há um fator comum de entendimento da espiritualidade/religiosidade como experiência singular de encontro com as outras pessoas, com o cosmos, com o transcendente e consigo mesmo. Adriana afirmou: "Porque é nessa relação do sujeito com o mundo que vai se construindo, é uma reciprocidade. (...) Deixar-se afetar por outras pessoas e pelos acontecimentos".

A capacidade de desenvolver e de cultivar valores foi apontada em alguns relatos como uma característica do sujeito que busca e cultiva, no seu cotidiano, a espiritualidade/ religiosidade. Como exemplo de alguns valores Salete citou:

Respeito pelas diferenças, reconhecimento do outro (outras pessoas, opiniões etc.), cuidado com a própria vida e a dos outros no sentido amoroso, não no sentido de obrigação de amar, na relação com o planeta, com outras formas de vida, no respeito pela vida de um modo geral.

O racionalismo foi destacado em quase todas as entrevistas como um dos aspectos centrais que interrompem o fluxo da experiência afetivo/espiritual. Fernando declarou: “A 
racionalidade pura não é suficiente. Hoje em dia as pessoas sentem necessidade de afeto, de ligação com outras pessoas". Para os entrevistados, a experiência significativa da espiritualidade/ religiosidade acontece a partir do momento em que o sujeito se deixa afetar pelas diversas formas em que o encontro acontece. Adriana relatou: "Poder deixar-se afetar um com o outro, poder olhar nos olhos, ouvir o que o outro está dizendo".

Em todas as entrevistas a prática religiosa foi apresentada sob dois aspectos: 1) Positiva, quando potencializa o sujeito, oferecendo-lhe um espaço coletivo que favorece e ajuda na sua organização, no sentir-se pertencente a algum lugar, a um grupo, a estar integrado com outras pessoas e a partilhar de suas experiências. De acordo com Adriana: "Nesse sentido potencializa e muitas vezes até dá um chão para o sujeito que está muito fragilizado, e porque se sente muito fragilizado, ajuda bastante". 2) Negativa, quando explora, manipula e atrapalha o processo de autonomia e o cultivo da própria espiritualidade, centrado mais em dogmas e cumprimentos de normas institucionais que culpabilizam. Nessa perspectiva, Adriana afirma: “Quando aprisiona o sujeito eu penso que seria um mau encontro porque despontecializa”.

\section{Clínica como autoconhecimento e como autonomia}

A clínica foi apresentada por todos os entrevistados como espaço privilegiado de produção de sentido e promoção da saúde mental, tanto individual como coletivamente. O desafio está em como pensar essa clínica como produção de saúde mental em quem está fragilizado pelo sofrimento. Adriana falou: "Como a clínica pode ser um operador de transformação, de cuidado, para potencializar saúde e vida?”. A clínica tem um papel fundamental para promover um encontro para além dos sintomas, possibilitando ao sujeito perceber o que causa sofrimento e desenvolvendo suas potencialidades. "Para que terapeuta e paciente, coordenador e grupo possam transformar isso em bom encontro ou trabalhar algum mau encontro" (Adriana).

Alguns entrevistados relataram que muitas pessoas com mal-estar procuram primeiro o espaço de alguma religião ou seguem a via da espiritualidade para encontrar uma resposta para o seu sofrimento. Todos estes movimentos denotam um desejo de sentido, de bem-estar espiritual e de saúde mental. Juliana afirmou: "É um primeiro sinal de que algo não vai bem e que ele precisa de uma coisa pra melhorar a vida, nem que ele coloque isso completamente fora dele, mas é uma ida, uma busca".

No processo terapêutico, todos entrevistados ressaltaram a importância da acolhida, da escuta e do respeito por parte do psicólogo. Ouvir significa respeitar a diferença do outro. Adriana afirmou: "Quando isso vem coletivamente a gente pode aprender a respeitar as diferenças ali no grupo". Alguns comentaram que a escuta psicológica, no processo terapêutico, assume um caráter de intervenção, quando se abre a possibilidade para que o sujeito repense a sua vida, suas práticas e como tudo chega afetá-lo. Denise disse: “Acolher e escutar, porque faz parte da singularidade da pessoa".

A acolhida e o respeito pela experiência de cada um foram apontados como facilitadores para estabelecer um vínculo de confiança na terapia. Para isso, é preciso tempo para que cada um faça o próprio processo. "Vai ter mil nomes que a gente vai poder dar pra isso, transferência, vínculos, confiança, um bom encontro e depois sim, construir junto com o sujeito" (Adriana).

A espiritualidade/religiosidade do usuário foi apontada como importante para a busca de autoconhecimento que promove a saúde integral do sujeito. Juliana afirmou que: "A busca por espiritualidade é uma busca por saúde mental”. O autoconhecimento é imprescindível tanto para o psicólogo quanto para o usuário/paciente. Fernando declarou: "A religiosidade ou a espiritualidade é uma busca de autoconhecimento".

Outros participantes citaram como algo importante para o autoconhecimento o processo de autonomia. Vera disse: "Esse conceito é um operador que pode ajudar a pensar a clínica. (...) Entra a religiosidade, a cultura, a escolaridade, o trabalho, enfim, tudo nesse sentido". O sujeito mais autônomo reflete mais sobre a vida, sobre como pratica a sua religiosidade, se é apenas por tradição. Juliana afirmou: "As pessoas passam a ser mais autônomas e passam a pensar se aquilo é uma coisa que elas querem continuar".

$\mathrm{Na}$ terapia, segundo os entrevistados, é necessário passar por esse processo de se questionar e se conhecer, não apenas resolver os sintomas. Fernando comentou: "Uma coisa é uma terapia voltada apenas para a resolução de sintomas, mas passado esse sintoma a pessoa vai começar a se tocar com outras questões maiores".

Muitos participantes fizeram referência às psicopatologias, afirmando que percebem uma estreita relação entre quadros de sofrimento psíquicos e expressões religiosas. Eles relataram exemplos de quadros psicóticos onde aparecem delírios com conteúdo religioso ou ligados a alguma forma de religiosidade. Fabiana exemplificou:

Um paciente, ...no surto dele, achou que ele era Jesus: deixou crescer a barba, o cabelo e foi pra outra cidade. Fez tatuar mensagens em todo o corpo: "eu sou enviado de Deus" e outros símbolos místicos. Ele tem esses símbolos até hoje. Saiu pregando com a Bíblia debaixo do braço.

Os entrevistados que relataram algum tipo de surto psicótico de seus pacientes afirmaram que estes sujeitos não conseguem localizar sua doença no corpo; depois de inúmeros exames sem resultados partem para algo relacionado com o espírito, colocando a doença no sobrenatural. Fabiana afirmou: "É uma necessidade deles, colocar numa coisa concreta algo que não tem explicação". Foi refletido que o corpo dá sinais de que algo não está bem e esses sinais vão se intensificando cada vez mais se o sujeito não dá atenção. Assim, o mal-estar, na opinião de alguns entrevistados, além de causar sofrimento, pode servir de alerta para a necessidade do cuidado da sua saúde, embora a pessoa não se dê conta desses sinais. Fernando afirmou: "A coisa vai cada vez tendo que ter sinais mais fortes e mais fortes e que podem chegar até a um surto ou a uma depressão grave".

\section{Discussão}

Saúde mental é um conceito abrangente e complexo, exigindo um olhar que integre as dimensões bio-psico-socioespiritual do ser humano, como foi constatado nas entrevistas. Na análise dos dados pode-se observar que a visão dos psicólogos 
entrevistados é afirmativa frente à relação entre saúde mental e espiritualidade/religiosidade. Embora tenha surgido definição de saúde mental, como equilíbrio entre as dimensões do ser humano, ela é pouco evidente na prática dos profissionais, sendo que a dimensão espiritual nem sempre é levada em consideração ou compreendida num contexto amplo da vida da pessoa.

Partindo do fato da queda das instituições, entre elas, as religiões, como um dos fatores que contribuem para o sentimento de vazio, pode-se perceber que, nesse contexto, a espiritualidade vem encontrando seu lugar como resposta aos anseios mais profundos do ser humano. Ao mesmo tempo, não se pode reduzir essa busca a uma mera satisfação de consumo social que não preencheria o vazio constituinte do ser humano. Este sentimento de "vazio existencial" que vem crescendo, colocando o sujeito numa posição de desamparo, na sintomatologia de Frankl (1989) é chamado de tríade da neurose de massa: a depressão, a agressão e a toxicodependência. Essa tríade estaria ligada ao sentimento de falta de sentido da vida. Para este autor, todos os seres humanos, além das suas necessidades comuns, sentem o desejo de sentido, em maior ou menor grau, como uma necessidade específica. Esse desejo é um "valor de sobrevivência".

Coelho e Mahfoud (2001), estudando as dimensões espiritual e religiosa da experiência humana na obra de Viktor Frankl, chegam à mesma conclusão de que a experiência religiosa faz parte da caminhada de uma vida plena de sentido. Nela o ser humano explora a força de sua dimensão espiritual, permitindo ser conduzido por uma realidade que o supera, e captando essa dinâmica na própria consciência.

$\mathrm{Na}$ inter-relação entre saúde mental e espiritualidade/ religiosidade, é importante perceber o quanto a segunda oferece recursos para enfrentar situações estressantes inevitáveis na vida, mantendo um bom nível de saúde (Pargament et al., 1998). A pesquisa mostrou que esses recursos vão surgir na medida em que o sujeito se abre e se deixa afetar pelos diversos encontros e experiências que a vida lhe proporciona: encontro com as demais pessoas, com o cosmos, com o transcendente e consigo mesmo. Toda experiência é singular e pode apresentar aspectos positivos e negativos. Segundo Pargament et al. (1998), a eficácia no enfrentamento a determinados estressores pode estar correlacionada com a integração de crenças, emoções, relacionamentos e valores, na resposta da pessoa a esses estressores. Os resultados negativos do enfrentamento são aqueles que apontam para uma quebra da integração interna, perda de valores religiosos, fortes sentimentos de raiva de Deus, dúvida ou confusão no seu sistema de crenças.

Por outro lado, para que essa inter-relação seja positiva e favoreça a saúde mental e intensifique a vivência espiritual do sujeito, vai depender do "sentido" e da forma como ele recebe e interpreta em seu contexto de vida essa experiência. A racionalização pode obstruir o fluxo da experiência afetiva espiritual, podendo ser um mecanismo de defesa que levaria o sujeito a um comportamento de justificar e explicar, de forma superficial a própria experiência, como foi apontado pelos psicólogos entrevistados.

Com esses resultados, pode-se pensar a clínica como espaço em que o psicólogo, enquanto facilitador do processo terapêutico, reconhece a dimensão da espiritualidade como parte inerente da relação estabelecida entre ele e o paciente, considerado um ser bio-psico-socio-espiritual. O psicólogo ocupa um importante lugar na fundamentação das diversas abordagens que reconhecem e trabalham com a dimensão espiritual no setting terapêutico (Saldanha, 1999). Pacientes que estabelecem uma relação de empatia e confiança com seus psicólogos/médicos se beneficiam mais do que outros que não a estabelecem. A confiança depositada no terapeuta desempenha um papel central na efetividade do tratamento e, por isso, deve ser cultivada eticamente (Peres, Moreira-Almeida, Nasello, \& Koenig, 2007).

É importante que os profissionais psicólogos saibam lidar adequadamente, na prática clínica, com sentimentos espirituais e comportamentos religiosos das pessoas atendidas. Para Moreira-Almeida et al (2006) e Tavares, Beria e Lima (2004) quatro questões sobre o papel da religiosidade na saúde mental do paciente são importantes investigar na prática clínica: 1) O paciente tem alguma forma de espiritualidade/religiosidade? 2) Pertence a uma comunidade religiosa? 3) Tem alguma crença espiritual que possa influenciar nos cuidados médicos? Qual a importância que o paciente atribui a estes aspectos da vida? 4) O paciente usa a religião ou a espiritualidade para ajudá-lo a lidar com sua doença, seu sofrimento, ou essas são fontes de estresse? Caso afirmativo, esta tem sido fonte de apoio ou de conflitos? Apresenta algum conflito ou questão espiritual que o preocupa? Tem alguém com quem conversar sobre estes tópicos?

Também a Associação Psiquiátrica Americana (American Psychiatric Association, 2006) recomenda alguns procedimentos para psicoterapeutas ao abordarem os temas espiritualidade e religiosidade: utilizar procedimento de entrevista para acessar o histórico e envolvimento com a religião e a espiritualidade; pesquisar o papel da religião e da espiritualidade no sistema de crenças; identificar se as idealizações religiosas e as representações de Deus são relevantes, e abordar clinicamente essa idealização; identificar se as variáveis religiosas e espirituais são características clínicas relevantes às queixas e aos sintomas apresentados; demonstrar o uso de recursos religiosos e espirituais no tratamento psicológico; treinar intervenções apropriadas sobre assuntos religiosos e espirituais e atualizar-se a respeito da ética sobre temas religiosos e espirituais na prática clínica.

Para Farris (2005), a psicologia/psicoterapia e a espiritualidade podem ser entendidas, apesar das diferenças fundamentais, como dois universos simbólicos que usam conceitos diferentes para descrever um processo semelhante de construção, percepção ou criação de significado, não sendo, portanto, incompatíveis. Porém, ele assinala pertinentemente, que é a orientação e abertura do psicólogo que determinará ou não o alcance da relação terapêutica, possibilitando ou impedindo o alcance da dimensão espiritual em psicologia. A espiritualidade/ religiosidade tanto pode expressar um processo maduro e bem integrado na busca de compreensão ou de significado para a vida, como também pode funcionar de maneira neurótica, defensiva ou adaptativa. Cabe ao psicólogo, com a devida abertura e capacitação, diferenciar e permitir a plena manifestação dessa estrutura humana no setting terapêutico.

Os resultados da pesquisa sugerem que o processo terapêutico que auxilia o sujeito a ir além dos sintomas é aquele 
que, além de trabalhar os sofrimentos, propicia um espaço vital de autoconhecimento, entendido aqui como espiritualidade. Para Fong (2009), o autoconhecimento é um processo que leva o sujeito a um encontro profundo consigo mesmo na sua interioridade, fazendo-o compreender por que reage a uma determinada situação, tornando-o capaz de fazer uma escolha mais consciente e, consequentemente, possibilitando saúde mental e um maior sentido de vida.

A viabilidade desse processo depende basicamente, segundo os entrevistados, da autonomia do sujeito. Essa pode ser definida como uma construção individual que perpassa a história de vida e, ao mesmo tempo, o contexto no qual o sujeito está inserido, mas não se reduz a ele. O cotidiano é uma possibilidade que o sujeito encontra de enfrentar o mundo, de forma que possa interferir nele e não se manter refém de determinações únicas, mas ser capaz de estabelecer relações pessoais e sociais em diversas instâncias. A autonomia diz também do quanto o sujeito consegue nesses encontros, nessa relação com o cotidiano, encontrar estratégias que permitam construir soluções para as dificuldades e os problemas que se apresentam, gerando suas próprias normas. Nesse processo de construção da autonomia o sujeito passaria a se relacionar e interagir com a sua comunidade, necessitando menos de dispositivos assistenciais (Moreira \& Andrade, 2003).

Com base nessa definição, pode-se concluir que o sujeito autônomo passaria a pensar sobre o sentido da sua vida e sobre a forma como a sua prática religiosa ou a sua espiritualidade o afetam, percebendo se elas são uma questão de escolha e como contribuem ou não para a sua saúde mental. Nesse sentido podese usar a reflexão de Jung (1987) sobre a relação da liberdade com a espiritualidade, quando ele diz que não se trata da liberdade de condições biológicas, psicológicas e sociais, pois a elas todo ser humano está submetido, mas da liberdade para uma tomada de posição diante das circunstâncias cotidianas ou excepcionais. Espiritualidade, segundo ele, é fazer a experiência fundadora dessa nova percepção da realidade e passar a cultivá-la.

A partir da experiência dos psicólogos do CAPS, o grupo psicoterapêutico tem um papel fundamental no processo de autonomia dos seus usuários e na construção do vínculo, favorecendo a troca de experiências, onde muitas vezes são trabalhados temas sobre religião e espiritualidade, partindo dos relatos dos próprios componentes do grupo. Segundo Cardoso e Seminotti (2006), esses grupos demonstraram ser um instrumento importante de estímulo à ampliação dos sujeitos que dele participam e devendo ser problematizados em sua complexidade e interdependência com a instituição e a realidade social em que se inserem. Essa ampliação implica múltiplas inclusões de sujeitos que, além de escolherem as suas maneiras de pertencer, também promovem a ampliação da pertença daqueles a quem se vinculam. No grupo, os usuários apresentam-se em cada sessão e ensaiam novas maneiras de pertencer, entendendo que, assim como o grupo apresenta inúmeras composições, eles também são múltiplos e podem ocupar seus lugares nos múltiplos vínculos em que participam (Cardoso \& Seminotti, 2006).

Um dos aspectos apontados na pesquisa foi de que muitas pessoas antes de chegarem para um atendimento psicológico já haviam passado por vários serviços, incluindo Igrejas, práticas religiosas e certas formas de espiritualidade, na tentativa de buscar alívio para seus sofrimentos. O desejo de compreender o que se passa consigo mesmo e encontrar uma solução para os sintomas são evidentes nas buscas desses sujeitos. Nesse contexto, os entrevistados colocaram que o respeito e a escuta por parte do psicólogo são condições básicas para que ocorra uma verdadeira acolhida e compreensão desse sujeito fragilizado, evitando o pré-conceito em relação às suas vivências religiosas ou espirituais. Corroborando essa ideia, Valle (2005) refere que, quando o terapeuta abre mão do papel de juiz da validade objetiva das crenças e vivências pessoais de quem ele acompanha psicologicamente, ele consegue tomar a sério a transcendência, enquanto dimensão humana. Para o autor, o ser humano nunca pode ser interpretado desde categorias redutivas, sejam elas psicológicas ou religiosas, mas sempre compreendido em sua complexidade. Também Peres, Simão e Nasello (2007) afirmam que a psicoterapia para reduzir sintomas e dificuldades do âmbito da saúde mental procura reconhecer e utilizar as crenças religiosas dos clientes em seus tratamentos.

Por outro lado, Dalgalarrondo (2008) explicita que vários autores evidenciam uma estreita relação entre psicopatologia e religião. Baseado em Schneider, ele afirma que, embora se diga que na base dos transtornos mentais estão causas físicas (demência, estados confusionais e psicose), como também causas psicológicas e sociais (neuroses, reações de adaptação e transtornos da personalidade), constata-se uma forte, recorrente e intensa presença do religioso na experiência dos pacientes, sejam eles acometidos por doenças mentais de base ou psicogênicas. $\mathrm{O}$ desafio em questão é avaliar a que tipo de experiência se refere e que consequências elas acarretam para o sujeito.

Dalgalarrondo (2008), citando Sanctis, explica que os transtornos mentais estão relacionados a conteúdos religiosos e espirituais como sendo um movimento, um deslocamento de energia psíquica vital de áreas afetivas importantes que se transfere, num jogo de forças particulares de um objeto para outro, para construir os novos objetos religiosos, o que ele chama de "conversão religiosa" ou como definiu Freud "sublimação". Para o autor, essa conversão é produzida por processos psíquicos e sociais, podendo ser considerados como fenômenos normais ou patológicos, como no caso de delírios e alucinações em doentes mais graves. Na conversão, o objeto de fé receberia toda a concentração da força afetiva.

Dando continuidade, Dalgalarrondo (2008) apresenta aspectos importantes para distinguir entre uma experiência mística espiritual e uma conversão patológica. Enquanto as verdadeiras alucinações dos psicóticos são preenchidas por conteúdos religiosos, as experiências de vida religiosa cotidiana, mesmo as arrebatadoras, são estados normais de consciência. Conclui dizendo que a psicologia deveria ater-se à presença do religioso na verdadeira doença mental, algo qualitativamente bem diferente da experiência positiva de religiosidade.

Ampliando a reflexão, Dalgalarrondo (2008), citando Sims, diz que as crenças religiosas, mesmo as excessivas e radicais, não são as causas dos delírios religiosos. Os delírios religiosos verdadeiros provêm de um adoecimento mental de base como a esquizofrenia, os quadros maníacos e depressivos psicóticos e outras psicoses, e sua manifestação vai depender do 
background social do paciente, de seus interesses e dos de seu grupo sociofamiliar. Assim, o adoecimento mental teria como base algo "endógeno" e não "sociocultural", que apenas ajuda para sua expressão, refletindo as preocupações, os valores e os interesses do seu meio cultural, que não podem ser apontados como fatores causais.

Todos os psicólogos entrevistados foram unânimes quanto à importância para a saúde mental de se reconhecer e valorizar as experiências espirituais, independente da prática religiosa. Embora exista certa dificuldade entre os profissionais de psicologia em compreender e definir de forma distinta espiritualidade/religiosidade e religião, bem como articular esses temas com a prática clínica, foi verificado que a espiritualidade está presente nas atividades dos psicólogos e nos processos terapêuticos dos usuários.

\section{Considerações finais}

A análise dos dados demonstrou que a espiritualidade/ religiosidade, quando bem integrada na vida do sujeito, contribui de forma positiva para a sua saúde mental. Com base nos resultados obtidos, é importante salientar que a definição de espiritualidade/religiosidade como "experiência" deve levar em consideração a forma como o sujeito se deixa afetar e como interpreta essas experiências, e o que ela produz enquanto sentido para a sua vida.

Na prática clínica, o psicólogo é um facilitador no processo de autoconhecimento e autonomia na integração com a dimensão espiritual. A escuta da experiência espiritual na atividade do profissional e a capacidade de deixar-se afetar, pode favorecer uma intervenção qualificada no campo da espiritualidade.

Na pesquisa, apareceu que as manifestações da psicopatologia estão mais relacionadas com a religião e não com a experiência espiritual em si, pois aspectos psíquicos desordenados encontram na vivência religiosa do sujeito um lugar de simbolização do seu sofrimento psíquico. Assim, a origem da psicopatologia não está propriamente na religiosidade, mas ela usa a religião como lugar de simbolização. Sendo assim, é importante distinguir, no processo psicoterapêutico, entre a experiência positiva e a qualidade de vida do sujeito, daquela que não contribui para a sua saúde mental.

Apesar do crescente número de pesquisas que se dedicam a investigar a relação positiva entre saúde mental e espiritualidade/ religiosidade, essa relação não encontra um lugar de relevância na formação do psicólogo. Os dados demonstram a importância de que a espiritualidade/religiosidade do usuário seja reconhecida e valorizada pelos profissionais como um recurso que favorece a sua saúde mental. Por isso, torna-se relevante criar espaços de discussão e esclarecimento sobre os conceitos de espiritualidade/ religiosidade e sua relação com a saúde mental também no âmbito universitário, realizando pesquisas sobre as interfaces entre essas duas realidades humanas e estudando estratégias quanto a sua presença na clínica.

\section{Referências}

American Psychiatric Association (2006). Religious/spiritual commitments and psychiatric practice. Recuperado de http://www.psych.org/ edu/other_res/ lib_archives/archives/200604.pdf

Berger P. L. (1997). Um rumor de anjos: a sociedade moderna e a redescoberta do sobrenatural. Petrópolis: Ed. Vozes.

Boff, L (2006). Espiritualidade: um caminho de transformação. Rio de Janeiro: Sextante.

Cardoso, C., \& Seminotti, N. (2006). O grupo psicoterapêutico no CAPS. Ciência e Saúde Coletiva, 11(3), 775-783. Recuperado de http://www.scielosp.org/ scielo.php?script $=$ sci_arttext\&pid=S1413-81232006000300025\&lng=pt $\&$ nrm $=$ iso

Coelho, A. G., \& Mahfoud, M. (2001). As dimensões espiritual e religiosa da experiência humana: distinções e inter-relações na obra de Viktor Frankl. Psicologia USP, 12(2), 95 - 103. Recuperado de http://www.scielo.br/scielo. php?script=sci_arttext\&pid=S0103 65642001000200006\&lng=pt\&nrm=iso

Connelly, R., \& Light, K. (2003). Exploring the "new" frontier of spirituality in health care: identifying the dangers. Journal of Religion and Health, 42(1), 35-46. Recuperado de http://www.ingentaconnect.com/content/klu/jorh/20 03/00000042/00000001/00457710

Dalgalarrondo, P. (2007). Estudos sobre religião e saúde mental no Brasil: histórico e perspectivas atuais. Revista de Psiquiatria Clínica, 34(1), 25-33. Recuperado de: http://www.scielo.br/scielo.php?script=sci arttext\&pid=S0101-60832007000700005\&lng=en\&nrm=iso

Dalgalarrondo, P. (2008). Religião, psicopatologia e saúde mental. Porto Alegre: Artmed.

Eliade, M. (1992). O sagrado e o profano: a essência das religiões. São Paulo: Martins Fontes.

Farris, J. R. (2005). Aconselhamento psicológico e espiritualidade. In M. M. Amatuzzi (Org.), Psicologia e espiritualidade. (pp. 161-172) São Paulo: Paulus.

Fong, S. N. (2009). A importância do autoconhecimento. São Paulo: Instituto União. Recuperado de http://www.institutouniao.com.br/artigos/ autoconhecimento.asp

Frankl, V. E. (1989). Um sentido para a vida. Aparecida, SP: Ed. Santuário.

Giddens, A. (2002). Modernidade e identidade. Rio de Janeiro: Jorge Zahar Editores.

Jung, C. G. (1987). Psicologia e religião. Petrópolis: Vozes.

Lancetti, A., \& Amarante, P. (2006). Saúde mental e saúde coletiva. In G. Campos et al. (Orgs), Tratado de saúde coletiva. (pp. 615-634) São Paulo; Rio de Janeiro: Hucitec; Fiocruz.

Libanio, J. B. (2002). A religião no início do milênio. São Paulo: Loyola.

Lukoff, D. (2003). Emergência espiritual e problemas espirituais. In Anais do $4^{o}$ Congresso Internacional de Psicologia Transpessoal. Cascais (Portugal): Associação Luso Brasileira de Psicologia Transpessoal. Recuperado de http://www.espacoguia.com.br/index.php?option=com_content\&view=arti cle\&id=90:apresentacao-do-dr-david-lukoff- \&catid=27:artigos\&Itemid=118

Minayo, M. C. S. (2000). O desafio do conhecimento. Pesquisa qualitativa em saúde. São Paulo: Ed. Hucitec-Abrasco.

Minayo, M. C. S., Hartz, Z. M. A., \& Buss, P. M. (2000). Qualidade de vida e saúde: um debate necessário. Ciência e Saúde Coletiva, 5(1), 7-18. Recuperado de http://www.scielo.br/scielo.php?script=sci_arttext\&pid=S1413$81232000000100002 \& \operatorname{lng}=$ en\&nrm=iso

Moreira-Almeida, A. (2007). Espiritualidade e saúde: passado e futuro de uma relação controversa e desafiadora. Revista de Psiquiatria Clínica, 34(1), editorial.

Moreira-Almeida, A., Lotufo Neto, F., \& Koenig, H. G. (2006). Religiosidade e saúde mental: uma revisão. Revista Brasileira de Psiquiatria, 28(3), 242-250. Recuperado de http://www.scielo.br/scielo.php?script=sci arttext\&pid=S1516-44462006000300018\&lng=en\&nrm=iso

Moreira, M. I. B., \& Andrade, A. N. (2003). Ouvindo loucos: construindo 
possibilidades de viver com autonomia. Psicologia, Saúde e Doenças, 4(2), 249-266. Recuperado de http://www.scielo.oces.mctes.pt/scielo. php?script=sci_arttext\&pid=S1645-00862003000200006\&lng=pt\&nrm=iso

Otto, R. (1985). O Sagrado: um estudo do elemento não-racional na ideia do divino e sua relação com o racional. São Paulo: Imprensa Metodista (Obra original publicada em 1915).

Panzini, R. G., \& Bandeira, D. R. (2005). Escala de coping religioso-espiritual (Escala CRE): elaboração e validação de construto. Psicologia em Estudo, 10(3), 507-516. Recuperado de http://www.scielo.br/scielo.php?script=sci arttext\&pid=S1413-73722005000300019\&lng=en\&nrm=iso

Pargament, K. I., Zinnbauer, B. J., Scott, A. B., Butter, E. M., Zerowin, J., \& Stanik, P. (1998). Red flags and religious coping: identifying some religious warning signs among people in crisis. Journal of Clinical Psychology, 54(1), 77-89. Recuperado de http:/www3.interscience.wiley.com/cgi-bin/ fulltext/106557151/PDFSTART

Peres, J. F. P., Moreira-Almeida, A., Nasello, A. G., \& Koenig, H. G. (2007). Spirituality and resilience in trauma victims. Journal of Religion and Health, 46(3), 343-350. Recuperado de http://www.springerlink.com/content/ q71246x638247925/fulltext.pdf

Peres, J. F. P., Simão, M. J. P., \& Nasello, A. G. (2007). Espiritualidade, religiosidade e psicoterapia. Revista de Psiquiatria Clínica, 34(1),
136-145. Recuperado de http://www.scielo.br/scielo.php?script=sci arttext\&pid=S0101-60832007000700017\&lng=en\&nrm=iso

Saldanha, V. (1999). A Psicoterapia transpessoal. São Paulo: Rosa dos Tempos. Stroppa, A., \& Moreira-Almeida, A. (2008). Religiosidade e saúde. In M. I. Salgado \& G. Freire (Orgs.), Saúde e espiritualidade: uma nova visão da medicina (pp. 427-443). Belo Horizonte: Inede.

Tavares, B. F., Beria, J. U., \& Lima, M. S. (2004). Factors associated with drug use among adolescents in Southern Brazil. Revista de Saúde Pública, 38(6), 787-796. Recuperado de http://www.scielo.br/scielo.php?script=sci arttext\&pid=S0034-89102004000600006\&lng=en\&nrm=iso

Vasconcelos, E. M. (2006). A espiritualidade no cuidado e na educação em saúde In E. M Vasconcelos (Org.), A espiritualidade no trabalho em Saúde (pp. 13-157). São Paulo: Hucitec.

Valle, J. E. R. (2005). Religião e espiritualidade, um olhar psicológico. In M. M. Amatuzzi (Org.), Psicologia e espiritualidade (pp. 83-107). São Paulo: Paulus.

Volcan, S. M. A., Sousa, P. L. R., Mari. J J., \& Horta, B. L. (2003). Relação entre bem-estar espiritual e transtornos psiquiátricos menores: estudo transversal. Revista de Saúde Pública, 37(4), 440-445. Recuperado de http://www.scielosp.org/scielo.php?script=sci_arttext\&pid=S0034$89102003000400008 \& \operatorname{lng}=\mathrm{en} \& \mathrm{nrm}=\mathrm{iso}$

Márcia Regina de Oliveira, mestranda em Psicologia pela Universidade do Vale do Rio dos Sinos, é encarregada da Estratégia de Humanização hospitalar do Hospital Banco de Olhos de Porto Alegre. Endereço para correspondência: Caixa Postal 101 (UNISINOS). CEP 93001-970. São Leopoldo, RS. Telefone: (51) 9767-3133. Fax: (51) 3081-4843. Email: marciafscj@yahoo.com.br

José Roque Junges, doutor em Ética pela Pontificia Università Gregoriana (Roma, Itália), pós-Doutor em Bioética pelo Boston College, é professor e pesquisador do PPG em Saúde Coletiva da Universidade do Vale do Rio dos Sinos. E-mail: roquejunges@hotmail.com 


\section{Pestidion de posicologia}

\section{ERRATA}

No fascículo 17, no. 3, p.469-476, artigo Saúde mental e espiritualidade/religiosidade: a visão de psicólogos de autoria de Márcia Regina de Oliveira \& José Roque Junges, há a seguinte correção de informação nos dados sobre os autores:

Márcia Regina de Oliveira, mestranda em Psicologia pela Universidade do Vale do Rio dos Sinos, é encarregada da Estratégia de Humanização hospitalar do Hospital Banco de Olhos de Porto Alegre. Endereço para correspondência: Caixa Postal 101 (UNISINOS). CEP 93001-970. São Leopoldo, RS. Telefone: (51) 9767-3133. Fax: (51) 3081-4843. Email: marciafscj@yahoo.com.br 